\title{
Spotlight on measles 2010: Measles outbreak in the Provence-Alpes-Côte d'Azur region, France, January to November 2010 - substantial underreporting of cases
}

C Six (Caroline.SIX@ars.sante.fr) ${ }^{1}$, J Blanes de Canecaude ${ }^{2}$, J L Duponchel ${ }^{2}$, E Lafont ${ }^{2}$, A Decoppet ${ }^{2}$, M Travanut ${ }^{2}$, J M Pingeon ${ }^{2}$, L Coulon ${ }^{2}$, F Peloux-Petiot ${ }^{2}$, P Grenier-Tisserant ${ }^{2}$, J C Delarozière ${ }^{3}$, F Charlet $^{2}$, P Malfait $^{1}$

1. Regional Office of the French Institute for Public Health Surveillance (Cire Sud), Marseilles, France

2. Regional Health Agency (Agence régionale de santé, ARS) of Provence-Alpes-Côte d’Azur, Marseille, Avignon, Digne-les-Bains, Gap, Nice, Toulon, France

3. Interregional infection control coordinating centre (CClin), Marseilles, France

Citation style for this article:

Six C, Blanes de Canecaude J, Duponchel IL, Lafont E, Decoppet A, Travanut M, Pingeon JM, Coulon L, Peloux-Petiot F, Grenier-Tisserant P, Delarozière IC, Charlet F, Malfait P. Spotlight on measles 2010: Measles outbreak in the Provence-Alpes-Côte d'Azur region, France, January to November 2010 - substantial underreporting of cases. Euro Surveill. 2010;15(50):pii=19754. Available online: http://www.eurosurveillance.org/ViewArticle.aspx?Articleld=19754

Article published on 16 December 2010

In 2010, the Provence-Alpes-Côte d'Azur region in France has been experiencing a measles outbreak with at least 310 cases among the general population, which included 28 cases among healthcare workers ( $9 \%$ of all reported cases). There is, however, substantial underreporting in the notification systems of cases in both populations.

\section{Background}

In the Provence-Alpes-Côte d'Azur (PACA) region in France, the measles virus currently circulates in the general population [1]. Outbreaks have occurred in welldefined groups such as nomadic minorities and Roma communities that are not fully vaccinated, in childcare centres, schools, universities, healthcare facilities and a prison. Hospitals have been particularly affected, as many measles cases visited emergency units or were admitted to hospital with complications.

In France, clinicians and microbiologists are requested to report suspected measles cases immediately to the regional public health authority (Agence régionale de santé, ARS), through the national mandatory notification system. The French Institute for Public Health Surveillance (Institut de veille sanitaire, InVS) collects and analyses this information. Where there is nosocomial infection, healthcare facilities are requested to notify the interregional infection control coordinating centres and the Agence régionale de santé, which in turn inform InVS, through the national early warning system [2]. As described fully elsewhere [1,2], the reporting includes the nature of the event, its main characteristics, as well as investigations and control measures carried out, and assistance can be requested.

\section{Outbreak description}

General population (preliminary data)

In the PACA region $(4,780,986$ inhabitants) increased measles transmission continued to be recorded in 2010. We included in our analysis the notified clinical and laboratory-confirmed cases with a date of rash onset between January 2008 and November 2010 (preliminary data). A confirmed case can be: (i)

\section{FIGURE 1}

Incidence of reported measles cases, by district, ProvenceAlpes-Côte d'Azur region, France, January - November 2010

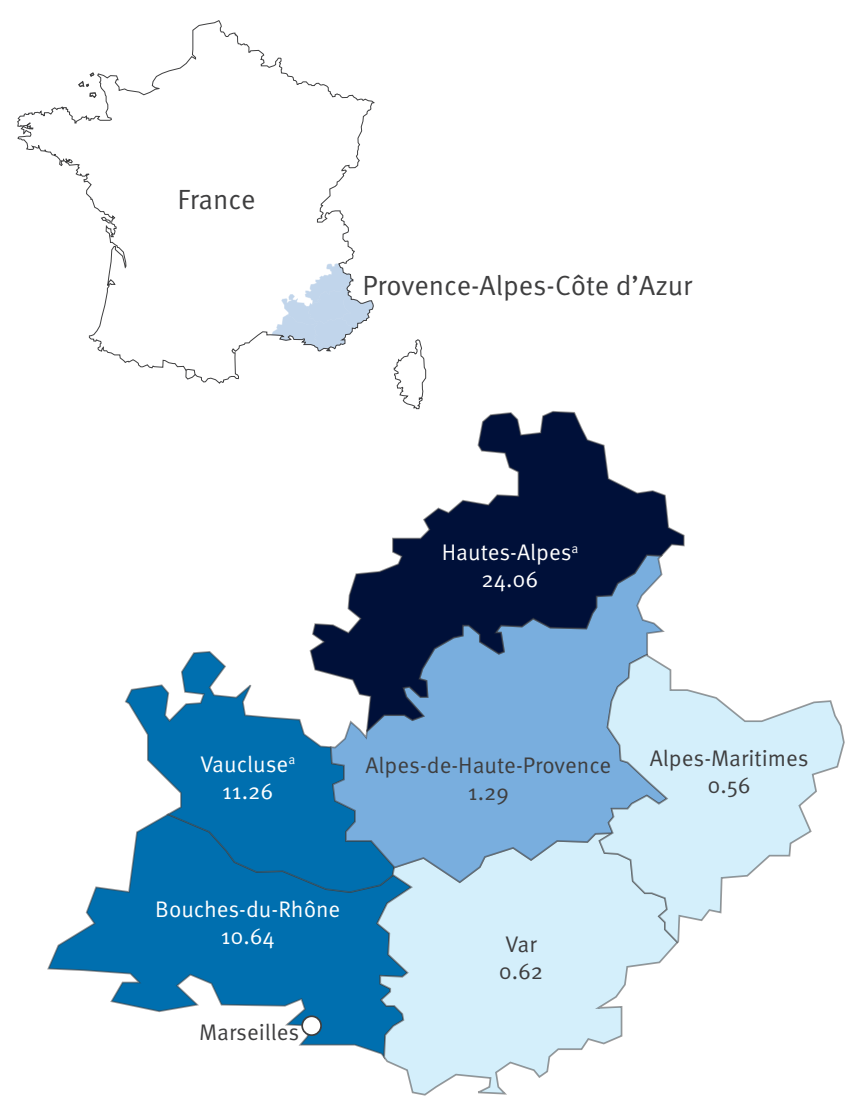

The numbers shown are the incidence rates per 100,000 population.

a Districts with active case finding.

Source : Regional Health Agency (Agence régionale de santé, ARS) of Provence-Alpes-Côte d'Azur, France. 
laboratory-confirmed, by detecting either measles IgM antibodies or measles virus nucleic acid in serum or oral fluid using reverse transcription-polymerase chain reaction (RT-PCR), or (ii) epidemiologically confirmed, when a link with a laboratory-confirmed case is proven. Case definitions for measles are detailed on the InVS website [3]. As of 30 November, 384 measles cases had been reported (Figure 1). In 2008 and 2009, 51 and 44 cases were reported.

In our analysis, 74 of the 384 cases reported in 2010 were excluded because detailed data were unavailable. The majority of cases, 193 of the remaining 310, were reported by the Bouches-du-Rhône district $(1,916,494$ inhabitants) (Figure 2); 126 of the 193 cases were reported by Marseilles ( 852,395 inhabitants), the biggest town of the region. In the PACA region, the incidence increased from 1.07 per 100,000 population in 2008 to 6.37 per 100,000 population in 2010 . The incidence in the Bouches-du-Rhône district reached 10.64 per 100,000 population and in Marseilles alone 14.78 per 100,000 population in 2010 (Figure 3). In France as a whole, 5,221 measles cases were reported between 1 January 2008 and 31 August 2010: the incidence rates in the general population increased from 0.95 per
100,000 population in $2008,2.3$ to 4.84 per 100,000 population in $2010[1,3]$.

The male:female ratio of the 310 measles cases in the PACA region was 1:2. The disease affected all ages, but the people most affected were those under one year $(10 \%$ of cases, $n=31)$ and $20-29$-year-olds $(25 \%$ of cases, $n=74)$. The highest incidence rate was observed in children under two years (51.07 per 100,000 population) (Figure 4).

Measles vaccination status was available in $81 \%$ of cases ( $n=250): 204$ ( $82 \%)$ were unvaccinated, $37(15 \%)$ had received a single dose of measles-mumps-rubella (MMR) vaccine, four (2\%) two doses and five ( $2 \%)$ unspecified number of doses.

The proportion of laboratory-confirmed cases was $58 \%(n=180)$ and the D4 genotype was identified in 13 samples.

Information on hospital admission was available for all cases except one; 98 (32\%) were admitted to hospital; of these, 29 were hospitalised in Marseilles.

\section{FIGURE 2}

Incidence of reported measles cases in Bouches-du-Rhône district, Provence-Alpes-Côte d'Azur region, France, January November 2010

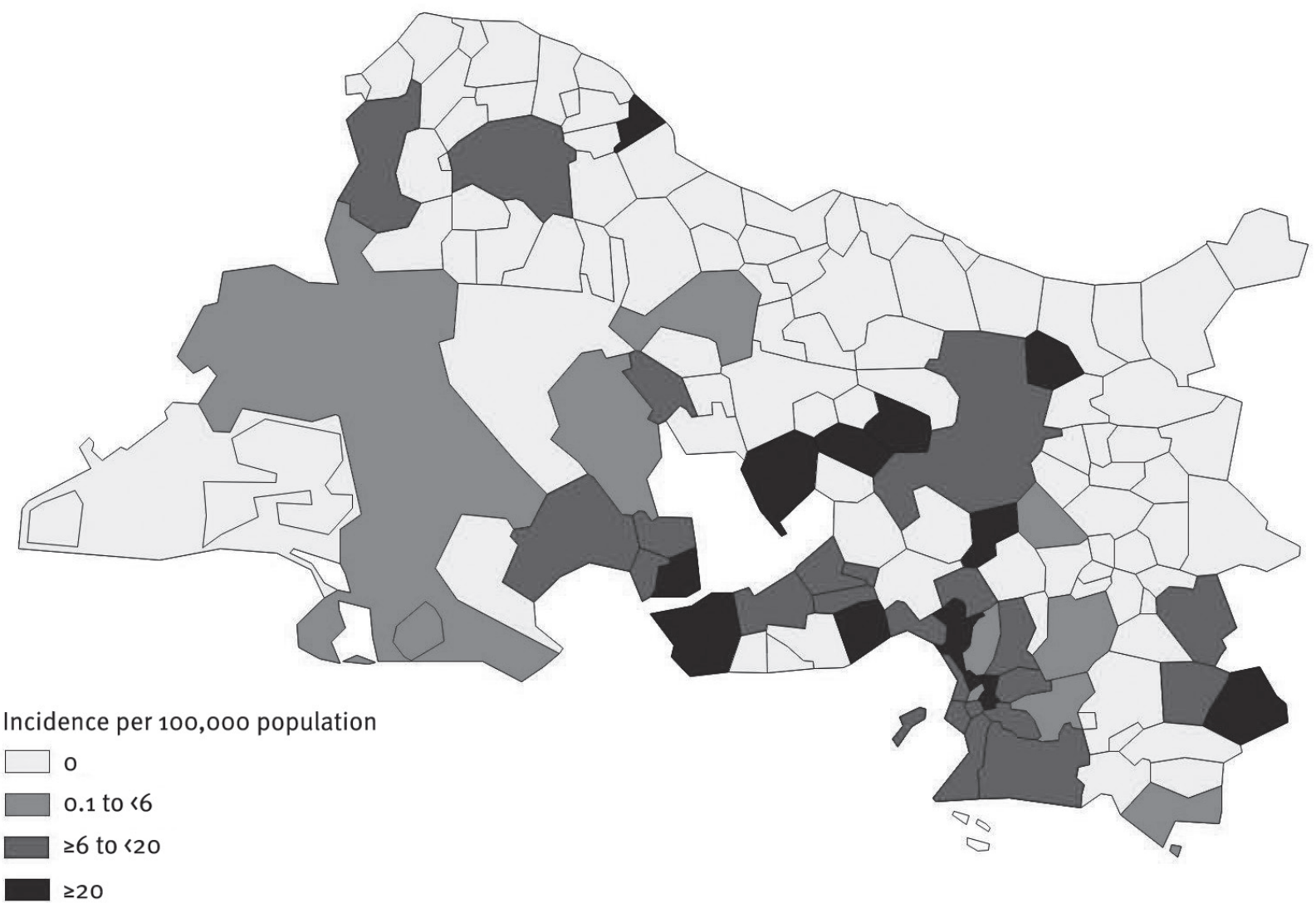

Source : Regional Health Agency (Agence régionale de santé, ARS) of Provence-Alpes-Côte d’Azur, France. 
A total of 34 cases had complications: 20 of these were in cases who had been hospitalised. There were no complications in infant cases, 11 cases with complications were aged 1-9 years, nine cases were 10-19 years and 14 were older than 20 years. Acute encephalitis was reported in an unvaccinated six-year-old case and pneumonia in 23 cases. No measles-related deaths were reported.

\section{Nosocomial infection of healthcare workers (preliminary data)}

In the PACA region, healthcare workers were particularly affected by measles, with 28 cases reported in 2010 (as of 30 November) through the mandatory notification system, representing $9 \%$ of all cases in the general population. Four cases were nurses, four were medical doctors, 11 were students (two nursing students and nine medical students) and seven were other types of healthcare workers; for two cases, their type of healthcare work was unspecified. Of these 28 cases, 23 were reported from Bouches-du-Rhône district; 15 of the 23 were from Marseilles. Only two of the 28 cases were reported through the early warning system.

\section{FIGURE 3}

Incidence of reported measles cases in Provence-AlpesCôte d'Azur region, France, by year, January 2008 -

November 2010

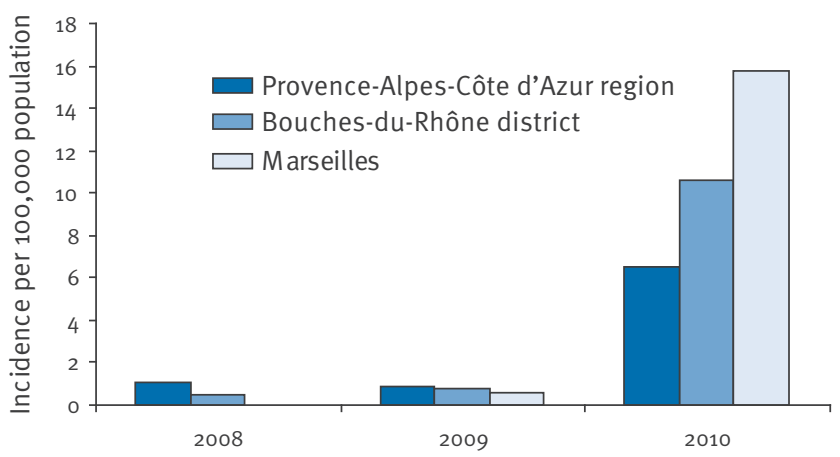

\section{FIGURE 4}

Incidence of reported measles cases in Provence-AlpesCôte d'Azur region, France, January 2008 - November 2010

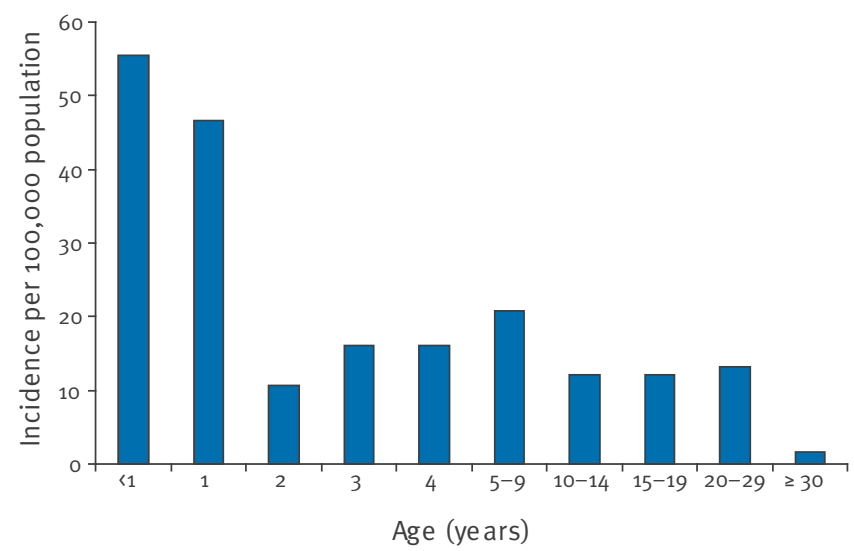

The male:female ratio of the 28 cases was $0: 6$. A total of 18 cases were aged 20-29 years and 10 were older than 30 years (the eldest was 55 years).

Measles vaccination status was known for 22 of the cases: 14 were unvaccinated, six had received a single dose of vaccine and two had had two doses.

Nine cases were admitted to hospital, of whom six were hospitalised in Marseilles.

\section{Control measures}

Several control measures were implemented by the Agence régionale de santé according to the national guidelines [4]. They included providing information to the general public and providing targeted information to healthcare professionals, by individual letter to general practitioners and heads of nursing schools in the Bouches-du-Rhône district. The communication was focused on vaccinating the general population and healthcare workers according to the national immunisation schedule and proposed post-exposure vaccination or immunoglobulin for people at high risk for severe disease as a result of measles virus infection.

During measles transmission among healthcare workers and/or hospitalised patients, most healthcare workers implemented barrier measures, and unvaccinated or non-immune healthcare workers and patients' contacts were vaccinated locally. Contacts outside the hospital, relatives and external patients that could have been infected by a case were identified, informed and invited to contact their general practitioner in order to ascertain their vaccination status and to complete their vaccinations if necessary.

\section{Discussion}

A high number of measles cases has been reported in 2010 in the PACA region, in particular in Marseilles. However, the number of measles cases reported is less than the true number of cases, for various reasons: cases were excluded from the analysis because of missing data, and clinicians and microbiologists did not report all cases to health authorities. InVS demonstrated that during investigations of measles outbreaks in 2008 , cases reported through the national mandatory notification system represented only $10 \%$ of all detected cases [5]. Often, only the first case in a household is reported: any secondary cases are not. The high proportion of hospitalised cases from the general population seems to reflect a better compliance in notification by their health professionals than by general practitioners.

In healthcare facilities, underreporting through mandatory notification and early warning systems is the main reason for underestimating the number of cases. For example, more cases have been identified by the public hospitals of Marseilles than have been declared to the Agence régionale de santé $[6,7]$. 
The low measles immunisation coverage among the general population and healthcare workers, who can infect vulnerable persons who they treat, facilitates the expansion of the outbreak in the region [8]. In 2007, among children aged 24 months, the vaccination coverage (one dose) reached $92 \%$ in the Alpes-Maritimes district, $89 \%$ in the Bouches-du-Rhône district and $87 \%$ in Var district (no data are available from the other districts of the PACA region); at national level, it was $90 \%$ [9]. Clinical diagnosis of measles cases must be better understood by general practitioners, and case notification and the implementation of preventive measures, including catch-up and post-exposure vaccinations, must be improved.

Insufficient implementation by healthcare workers and general practitioners of the current recommendations issued by the French health authorities [4] and unsuitable control measures in some healthcare facilities are the cause of measles transmission in healthcare workers and hospitalised patients [8]. Awareness among the healthcare workers, particularly occupational medical staff, must be raised to implement specially adapted preventive and control measures in hospitals units, especially in emergency rooms and wards where all patients admitted to hospital with rash and fever must be isolated and strict infection control procedures applied before diagnostic confirmation. Preventive measures need also to focus on improving the hospital's knowledge of the serological status of their patients and on vaccinating them if they are not immunised, because immunisation is the only reliable protection against nosocomial spread of measles [10].

\section{Acknowledgements}

We wish to thank the following persons who contributed to the development of the surveillance and the implementation of control measures of measles in France in general and in the PACA region (in alphabetical order): A.M. Belloc, K. Mauberret, E Mussetti, I. Parent du Châtelet, L. Pilagliano and I. Teruel. We also thank A. Backs and J. Deniau for the production of this article.

\section{References}

1. Parent du Châtelet I, Antona D, Freymuth F, Muscat M, Halftermeyer-Zhou F, Maine C, et al. Spotlight on measles 2010: Update on the ongoing measles outbreak in France, 2008-2010. Euro Surveill. 2010;15(36): $\mathrm{pii}=19656$. Available from: http://www.eurosurveillance.org/ViewArticle. aspx?Articleld $=19656$

2. RAISIN Working Group. "RAISIN" - A national programme for early warning, investigation and surveillance of healthcare-associated infection in France. Euro Surveill. 2009;14(46):pii=19408. Available from: http://www. eurosurveillance.org/ViewArticle.aspx?Articleld=19408

3. Institut de Veille Sanitaire (InVS). Données de declaration obligatiore de la rougeole - bilan de situation jusqu'au 31/08/2010. [Information from the mandatory declaration about measles - overview of the situation until 31/08/2010]. French. Available from: http://www.invs.sante.fr/surveillance/ rougeole/default.htm
4. Ministère de la santé et des sports. CIRCULAIRE NDGS/ $\mathrm{Rl} 1 / 2009 / 334$ du 4 novembre 2009 relative à la transmission obligatoire de données individuelles à l'autorité sanitaire en cas de rougeole et la mise en oeuvre de mesures préventives autour d'un cas ou de cas groupés [Circular No. DGS/RI1/2009/334 of 4 November 2009 on the mandatory notification of individual data to the health authority in case of measles and implementation of preventive measures around a case or a cluster]. French. Available from: http://www.sante. gouv.fr/IMG/pdf/o9_334topdf.pdf

5. I Parent du Châtelet, DAntona, D Waku-Kouomou, F Freymuth, C Maine, D Lévy-Bruhl. La rougeole en France en 2008: bilan de la déclaration obligatoire. [Measles in France in 2008 : results of the mandatory declaration]. French. Institut de Veille Sanitaire. Bull Epidemiol Heb. 2009;(39-40):415-9. Available from: http://www.invs.sante.fr/beh/2009/39_40/ beh_39_40_2009.pdf

6. La Provence. [Internet]. Rougeole: fièvre dans les hôpitaux marseillais. [Measles : fever in the hospitals of marseilles]. 5 Dec 2010. French. Available from: http://www.laprovence.com/ article/region/rougeole-fievre-dans-les-hopitaux-marseillais

7. Hospimedia. [Internet]. 227 cas de rougeole dans les Bouchesdu-Rhône. Plus d'un tiers des patients hospitalisés depuis le début de l'année. [227 cases of measles in Bouches du-Rhône. Over a third of patients hospitalised since the beginning of the year]. 6 Dec 2010. French. Available from: http://abonnes.hospimedia.fr/breves/plus_d_un_tiers_des patients hospitalises depuis le debut de I annee? $\mathrm{f}=\mathrm{AQN}$ $071210 \& \bar{u}=$ U0000038 $534 \& s=\overline{5} 2 \mathrm{ff}_{3} 6828 \mathrm{dbe} 837 \mathrm{cdafbbd} 36 \mathrm{~d}$ 1d39790\&utm_source=testeurs\&utm_medium =email \&utm campaign $=$ aq101207

8. Sillam F, Cua E, Faudeux D, Peloux-Petiot F, Negre A, Six C. Investigation d'une épidémie de rougeole avec transmissions nosocomiales en région Provence-Alpes-Côte d'Azur et dans la Principauté de Monaco, mars - mai 2008. Quels enseignements en tirer? [Investigation of a measles outbreak with nosocomial transmission in Provence-Alpes-Côted'Azur and in the Principality of Monaco, March-May 2008. What are the lessons learned?]. French. Bull Epidemiol Heb. 2009;(39-40):424-6. Available from: http://www.invs.sante.fr/beh/2009/39_40/ beh_39_40_2009.pdf

9. Six C. Organisation de la vaccination et mesure de la couverture vaccinale en région Provence-Alpes-Côted'Azur. [Organisation of vaccination and measurement of the vaccine cover in area the Provence-Alpes-Côted'Azur region]. Institut de Veille Sanitaire, Oct 2010. French. Available from: http:// www.invs.sante.fr/publications/2010/couverture vaccinale paca/rapport_couverturte_vaccinale_paca.pdf

10. Botelho-Nevers E, Chevereau L, Brouqui P. Letter to the editor. Spotlight on measles 2010: Measles in healthcare workers - vaccination should be revisited. Euro Surveill. 2010;15(41): pii=19687. Available from: http://www. eurosurveillance.org/ViewArticle.aspx?Articleld=19687 